\title{
GEREJA ADA UNTUK MENJALAKAN MISI ALLAH BAGI DUNIA DALAM PRESFEKTIF KITAB RUT
}

\section{STELAH NIPA}

\author{
Institut Agama Kristen Negeri Toraja
}

\section{Stelanipa@gamil.com}

\begin{abstract}
Abstrak : artikel ini membahas tentang kitab Rut menjadi bagian yang juga sangat penting dalam rencana penyelamatan Allah bagi manusia, dengan adanya tulisan ini bertujuan untuk mengetahui bagaimana dalam kitab Rut mengajarkan tentang kasih Allah yang tidak terbatas bagi manusia sehingga melalui itu kitab Rut memberikan juga teladan bagi gereja ada yang untuk menjalankan misi Allah, adapun yang menjadi latar belakang penulisan ini yaitu karena melihat kondisi gereja saat ini yang seakan tidak lagi menjalakan tugas dan perannya sebagaimana adanya, jika diteliti dengan seksama kita dapat melihat begitu banyak hal dalam gereja pada zaman ini yang bertolak belakang dengan Alkitabiah dan bahkan berjalan menurut pendapat mereka sendiri tidak lagi berpatokan dengan Alkitab.
\end{abstract}

Kata kunci : Misi, Gereja. Rut

Abstrack : This article discusses the meaning the book of Ruth is also a very important part in God's plan of salvation for humans, with this writing the aim is to find out how the book of Ruth teaches about God's unlimited love for humans so that through it the book of Ruth also provides an example for the church there to carry out God's mission, as for the background of this writing, because of the current condition of the church which seems no longer carrying out its duties and roles as it is, if we examine carefully we can see so many things in the church today that are contrary to the Bible and even walk in their own opinion no longer according to the Bible. 


\section{Pendahuluan}

Defenisi kata "misi" ada dua bentuk yaitu tunggal dan jamak. Misi tunggal adalah yang mengacu kepada mission Dei (misi Allah), artinya, penyataan diri Allah sebagai Dia yang mengasihi dunia ketelibatan Allah di dalam dan dengan dunia, sifat dan kegiatan Allah, yang merangkul gereja dan dunia serta dimana gereja. Misi adalah penyampaian kabar baik yaitu Allah adalah Allah untuk manusia. sedangkan definisi misi jamak (misi-misi) adalah (messiones ecclesiae, 'usaha-usaha mesioner gereja'), mengacu pada bentuk-bentuk khusus yang berhubungan dengan waktu, tempat, atau kebutuhan tertentu, dari partisipasi dalam mission Dei

Misi beranjak dari hati Allah, Allah yang berinisiatif untuk melaksanakan dan mencapai misi-Nya. Panggilan misi berasal dari Allah yang menjadikan orang percaya sebagai saksiNya, alatNya, pelayan-Nya, Utusan-Nya serta sebagai garam dan terang dunia. Misi adalah tindakan Allah Tritunggal Allah bapa yang tidak pernah berhenti berkarya di tengah-tengah ciptaan-Nya serta berkarya dalam hati dan pikiran manusia, tidak peduli manusia mengenalNya ataupun tidak.Di dalam misi Allah itu sendiri terdapat injil yaitu yang merujuk kepada Mesias.

Gereja merupakan suatu komunitas orang percaya dari kata ekklesia yang artinya di panggil keluar, Gereja menjadi komunitas atau bahkan juga organisasi yang memiliki pengaruh sangat tinggi dalam kehidupan umat manusia. Gereja menjadi sala satu tempat untuk memberitakan tentang kabar baik atau Injil kepada setiap orang mengenai Yesus Kristus dalam tindakan dan ucapanNya. Namun Gereja yang ada pada masa ini barulah menjadi gereja yang sebenarnya ketika mereka melibatkan diri atau terlibat dalam misi penginjilan dan pelayanan Allah di tengah dunia ini. Namun keterlibatan itu bukanlah hal yang mudah bagi gereja pada masa ini dan banyak tantangan dan rintangan yang harus mereka hadapi, untuk bisa menjalankan misi Allah bagi dunia yang telah di mandatkan kepada mereka bahkan menjadi tanggung jawab yang harus mereka bawah di pundak kemana pun mereka pergi. Namun tanggung jawab gereja bukan hanya melakukan misi tetapi juga mempunyai tugas untuk melakukan pelayanan kebutuhan bagi manusia secara umum.

Seperti yang bisa kita ketahui bahwa Amanat Agung Yesus bukan merupakan sebuah tantangan melainkan tanggung jawab yang harus dipikul, dan di peruntukan bagi semua orang percaya untuk bisa dan harus pergi sampai ke ujung dunia untuk memberitahukan Injil kepada segala makhluk,

Pada zaman ini banyak gereja yang sudah mengetahui bahkan mengerti dan memahami bahwa tugas mereka adalah untuk bermisi atau memberitahkan kabar keselamatan bagi mereka 
yang terhilang. Tetapi tidak dapat di pungkiri, bahwa di balik itu masih ada gereja yang sama sekali belum memahami tugas dan hakekat mereka yang sebenarnya, dan tidak memahami apa itu misi secara keseluruhan. Mereka hanya berfokus kepada bangunan gereja, persekutuan didalam gereja tanpa mau keluar dari zona nyaman mereka, bahkan ada juga yang masih terikat dengan kehidupan tradisional. Serta yang menjadi pengaruh besar adalah kurangnya wawasan dan pengajaran kepada mereka tentang Firman Tuhan mengenai misi, sehingga mereka tidak mengetahui makna dan arti dari misi itu sendiri.

Melihat hal tersebut maka saya tertarik untuk menulis tentang"Gereja ada untuk menjalankan Misi Allah".

\section{Tujuan dan Manfaat}

Tulisan ini bertujuan dan bermanfaat untuk memberikan pemahaman yang baik bagi jemaat dan juga setiap orang yang percaya bahwa Gereja ada untuk menjalankan misi Allah dunia dalam presfektif kitab Rut yang dimana didalam pemberitaan injil adalah tugas dan tanggung jawab yang yang harus kita lakukan dan juga pemahaman tentang kitab Rut yang tidak hanya membahas mengenai pernikahan antara Rut dan Boas tetapi juga mengadung makna tentang pentingnya misi Allah untuk kita lakukan sebagai orang yang percaya.

\section{PEMBAHASAN}

Injil bersifat menebus. Keselamatan di dalam kristus telah mempersatukan manusia dengan Allah. ini jauh melampaui pengajaran didalam agama-agam lain, baik dalam sifat kesempurnaan maupun sifat ketepatan; agama-agama lain hanya memiliki konsep penggantian (substitusi) yang kabur. Injil yang hanya bersifat menyelamatkan hanya terdapat terlihat dengan jelas di dalam wahyu Allah. Dalam visi misi Allah yang sempurna untuk manusia yang telah jatuh ke dalam dosa, sehingga Allah juga memakai salah satu tokoh dalam kitab Rut, yang menggambarkan karya keselamatan bagi seluruh bangsa, untuk mengenapi janji-Nya (Kej 3:15).

Penulisan kitab Rut sama halnya dengan penulisan kitab Hakim-Hakim, dalam penulisan kitab ini juga tidak jelas, kendati tradisi Yahudi menunjuk Samuel sebagai penulisnya. Nama kitab Rut diambil dari salah satu tokohnya, Rut, seorang wanita dari Moab, nenek buyut Daud dan salah satu wanita yang termasuk dalam sisilah Mesias (Mat 1:5).

Kitab Rut juga mengisahkan tentang loyalitas, integritas, dan cinta yang murni dalam

kekelaman masa Hakim-Hakim. Rut adalah figur iman dan ketaatan ditengah-tengah kemurtadan umat Allah. Rut telah membuktikan betapa Allah tetap setia kepada konvonan- 
Nya. Boaz dan Rut juga menjadi leluhur "Anak Daud”, Mesias, yang ditunggu-tunggu seluruh kaum pilihan-Nya. Dalam Perjanjian Lama, bila seseorang atau sebidang tanah dijual dalam perbudakan, mereka dapat tebusan melalui beberapa persyaratan yang harus dipenuhi oleh Kerabat-Penebus, hal ini merujuk kepada karya penebusan Juruselamat. Tujuan dari kitab Rut juga Nampak pada cara mengilustrasikan Boaz sebagai tipe 'penebus' bagi Rut. Kehadiran orang saleh pada masa kemurtadan, dan kesetiaan Allah terhadap mereka yang berjalan bersamanya memelalui iman. Bukankah suatu kejutan apabila seseorang mendapat kasih karunia Allah justru seorang wanita Moab, seteru Yahudi. Kitab ini menunjukan kerinduan Allah untuk membawa bangsa-bangsa lain ke dalam kerajaan Anak Daud. Dalam hal ini maka misi Allah sangatlah jelas dalam penebusan yang diilustrasikan dalam kitab Rut ini, dan penebusan itu bukan hanya kepada bangsa Yahudi tetapi juga kepada bangsa nonYahudi.

Dari hal ini kita dapat melihat bagaimana rencana dan misi Allah bagi dunia khususnya orang yang berdosa, kemudian gereja ada untuk merespon panggilan misi itu Allah menjalakan rencanaNya melaui Rut utnuk menghadirkan Yesus Kristus menjadi tebusan bagi banyak orang dengan demikian sebuah keharusan bagi gereja untuk menjalakan misi Injil bersifat menebus. Keselamatan di dalam kristus telah mempersatukan manusia dengan Allah. ini jauh melampaui pengajaran didalam agama-agam lain, baik dalam sifat kesempurnaan maupun sifat ketepatan; agama-agama lain hanya memiliki konsep penggantian (substitusi) yang kabur. Injil yang hanya bersifat menyelamatkan hanya terdapat terlihat dengan jelas di dalam wahyu Allah. Dalam visi misi Allah yang sempurna untuk manusia yang telah jatuh ke dalam dosa, sehingga Allah juga memakai salah satu tokoh dalam kitab Rut, yang menggambarkan karya keselamatan bagi seluruh bangsa, untuk mengenapi janji-Nya (Kej 3:15). Penulisan kitab Rut sama halnya dengan penulisan kitab Hakim-Hakim, dalam penulisan kitab ini juga tidak jelas, kendati tradisi Yahudi menunjuk Samuel sebagai penulisnya. Nama kitab Rut diambil dari salah satu tokohnya, Rut, seorang wanita dari Moab, nenek buyut Daud dan salah satu wanita yang termasuk dalam sisilah Mesias (Mat 1:5) Kitab Rut juga mengisahkan tentang loyalitas, integritas, dan cinta yang murni dalam kekelaman masa Hakim-Hakim. Rut adalah figur iman dan ketaatan ditengah-tengah kemurtadan umat Allah. Rut telah membuktikan betapa Allah tetap setia kepada konvonan-Nya. Boaz dan Rut juga menjadi leluhur “'Anak Daud”, Mesias, yang ditunggu-tunggu seluruh kaum pilihan-Nya

Dalam Perjanjian Lama, bila seseorang atau sebidang tanah dijual dalam perbudakan, mereka dapat tebusan melalui beberapa persyaratan yang harus dipenuhi oleh Kerabat-Penebus, hal ini merujuk kepada karya penebusan Juruselamat. Tujuan dari kitab Rut juga Nampak pada 
cara mengilustrasikan Boaz sebagai tipe 'penebus' bagi Rut. Kehadiran orang saleh pada masa kemurtadan, dan kesetiaan Allah terhadap mereka yang berjalan bersamanya memelalui iman. Bukankah suatu kejutan apabila seseorang mendapat kasih karunia Allah justru seorang wanita Moab, seteru Yahudi. Kitab ini menunjukan kerinduan Allah untuk membawa bangsabangsa lain ke dalam kerajaan Anak Daud. 1Dalam hal ini maka misi Allah sangatlah jelas dalam penebusan yang diilustrasikan dalam kitab Rut ini, dan penebusan itu bukan hanya kepada bangsa Yahudi tetapi juga kepada bangsa non-Yahudi.

ission Dei merupakan titik tolak dalam memulai penyelidikan tentang hakikat misi ${ }^{2}$. Dimana missio Dei memberitahkan kabar baik bawa Allah adalah Allah untuk manusia ${ }^{3}$. Misi Allah diungkapkan melalui keseluruhan pekerjaannya untuk menyelamatkan dunia dan segala isinya kepedulian Allah terhadap manusia dan segala ciptaannya diwujudkan dengan cara mengutus Yesus kristus ke dalam dunia untuk menyelamatkan umat manusia dari hukuman dosa

J.Andrew Krik dalam bukunya,Apa itu Misi? mengatakan bahwa misi adalah realitas mendasar tentang kehidupan kekristenan. lebih lanjut dijelaskan bahwa orang kristen dipanggil oleh Allah untuk bekerja denganNya, di dalam mencapai tujuannya panggilan umat manusia secara keseluruhan. Hidup di dunia ini adalah kehidupan di dalam misi hidup hanya mempunyai tujuan selamanya mempunyai dimensi missioner. ${ }^{4}$

Sedangkan menurut Artanto misi adalah tugas total dari Allah yang mengutus gereja untuk keselamatan dunia. Misi Allah adalah aktivitas Allah yang mencakup dunia, yang didalamnya gereja memperoleh hak istimewa untuk ikut ambil bagian ${ }^{5}$. Pada dasarnya hartanto melihat bahwa misi gereja adalah keterlibatan gereja dalam misi kerajaan Allah sebab apa yang hendak dilaksanakan oleh gereja di tengah dunia ini adalah bagian dari kehendak Allah yakni memberitakan tentang kehadiran kerajaan Allah itu sendiri.

Jadi misi dapat diartikan sebagai tugas yang berasal dari Allah untuk menyelamatkan dunia, dan di amanat kan kepada orang percaya yang sekaligus menjadi tugas dan panggilan kerja di tengah dunia ini Tuhan Allah sendiri adalah rangkaian dari misi Allah yang menghendaki dunia dan segala isinya diselamatkan dan Allah telah melakukan penyelamatan tersebut di atas pusat dalamnya Yesus kristus sebagai penebus sehingga manusia terbebas dari

\footnotetext{
1 David j. Bosch. Transformasi Misi Kristen.(1996: Jakarta. BPK gunung mulia). HIm. 15.

${ }^{2}$ Ibid, h. 15

${ }^{3}$ Ibid,h.27

${ }^{4}$ J.Andrew Kirk, Apa Itu Misi?, (Jakarta :BPK Gunung Mulia,2012),h.36

${ }^{5}$ Widi Artanto,Menjadi Gereja Yang Misioner,(Jakarta :BPK Gunung Mulia, 2010), h.62
} 
perbudakan dosa. Gereja sebagai persekutuan orang percaya harus ikut dalam panggilan bermisi ditegaskan dalam mengabarkan kabar sukacita dari Allah kepada dunia. Dalam kamus besar bahasa indonesia kata gereja di artikan sebagai gedung atau rumah tempat manusi melakukan upacara keagamaan kristen ${ }^{6}$. Pengertian lain tentang gereja juga dikatakan oleh calvin bahwa Gereja adalah sarana yang diberikan oleh Allah kepada orang percaya yang ada, untuk membina dan memelihara mereka dalam iman. ${ }^{7}$ Dan sekali-kali tidak boleh diabaikan manusia seakan-akan mampu memelihara diri sendiri dalam kebenaran di mana dari beberapa segi didefinisikan sebagai persekutuan orang percaya yang ingin beribadah kepada Allah atau biasa merupakan ungkapan imanmu kamu percaya kepada Allah.

Sehingga dapat disimpulkan bahwa gereja adalah persekutuan umat percaya yang dipanggil oleh Allah, untuk memberitakan kerajaannya dibuka bumi ini oleh karena itu manusia perlu membangun persekutuan untuk bersama-sama bertumbuh dalam iman kepada Yesus kristus. adapun gereja memiliki beberapa sifat-sifat yaitu kudus, am dan satu. Serta memiliki fungsi sebagai tempat persekutuan dan juga sebagai organisme yang hidup.

Dilihat dari pengertian misi di atas maka kita dapat memberi pemahaman bahwa gereja dan misi adalah sesuatu hal yang tidak dapat dipisahkan. kegiatannya saja yang dilakukan merupakan hal yang berkaitan dengan misi, dan merupakan cita-cita ya yang harus dinyatakan oleh Yesus agar tidak ada kawanan domba yang hilang, semuanya dapat diselamatkan menjadi satu $^{8}$. ketika Tuhan Allah menyelesaikan tugasnya di dalam dunia ini dia membawa murid Murid dan pengikutnya, untuk berkumpul di suatu bukit yang disebut bukit zaitun. Dalam kitab injil khususnya di kitab matius hal tersebut dijelaskan bahwa pada saat itu Tuhan Yesus, membebankan tugas yang cukup berat kepada pengikutnya. Yaitu menjadikan semua bangsa muridNya dan memberitakan injil ke seluruh dunia. panggilan ini merupakan tugas atau amanat agung dalam mengemban tugas dan pelayanan. Sejarah akustik gereja harus mampu menjalankan visi dan misi dari Allah kepada dunia yaitu, mewujudkan dan memuridakan mereka yang terhilang untuk bermisi dan memberitakan injil di antara suku bangsa bahkan sampai ke ujung dunia, secara efektif menarik perhatian orang serta meyakinkan dan mengumpulkan mereka, menjadi orang yang percaya membentuk persekutuan atau jemaat, kemudian membimbing dan mendidik mereka untuk mempunyai iman yang kokoh di dalam

\footnotetext{
${ }^{6}$ Kamus Besar Bahasa Indonesia, Pusat Pembinaan dan Pengembangan Bahasa,(Jakarta :Balai Pustaka, 1995),h.313

${ }^{7}$ Cristian De Jong,Apa Itu Calvinisme,(Jakarta :Gunung Mulia,2001),h.99

${ }^{8}$ Proyek Pembinaan Calon Tenaga Kependidikan, Agama Kristen,(Jakarta:Sekretariat,Jendral Depertemen Agama RI,2003),h.14
} 
Tuhan. Kemudian selanjutnya melatih setiap jemaat untuk memberitakan injil dan mengajarkan Amanat agung itu sehingga mereka bisa menjadi duta duta kristus ke seluruh dunia. Sebagai seorang yang telah dipilih kristus maka sepatutnya la kita bersaksi mengikuti persekutuan melakukan pelayanan dan juga mengajarkan Firman Tuhan. Di lihat dari pemaparan di atas maka dengan jelas kita dapat menyimpulkan bahwa Gereja mempunyai tugas dan tanggung jawab yang teramat penting ${ }^{9}$, apalagi jika melihat perkembangan zaman yang semakin modern, gereja-gereja yang ada harus mempunyai semangat yang tinggi dan pantang menyerah dalam menjalankan Amanat Agung tersebut. Karena sejak dari perjanjian lama sampai pada masa perjanjian baru pun Dalam Alkitab memberikan banyak contoh tentang Nabi dan juga rasul, yang dipilih untuk melakukan misi memberitahkan kabar baik.

Oleh sebab itu gereja harus melihat dari segi rohani bahwa sekarang ini banyak jiwa yang terhilang yang membutuhkan arahan dan terang untuk mendapatkan keselamatan, bahkan juga tidak dapat di pungkiri bahwa sebagain besar warga jemaat dalam sebuah gereja ada yang telah jauh dan masuk dalam kategori domba yang hilang. maka dari itu gereja harus jeli melihat keadaan, serta mikirkan metode pelayanan apa yang harus di lakukan agar gereja tersebut menjadi gereja yang sungguh-Sungguh menjalakan misi Allah bagi Dunia ini. Memuridkan jemaat ,dan memberi pemahaman tentang makna misi itu sendiri. sehingga mereka juga bisa keluar dan menjadi garam dan terang dimanapu mereka berada, dan memberitahkan kabar baik kepada mereka yang belum mengenal Tuhan. Gereja mempunyai peran yang sangat penting bagi jemaat, dengan memberitahkan Firman yang murni kemudian mengutus mereka untuk Memuridkan dan melipatganda sehingga semua orang bisa percaya kepada Allah bahkan sampai ke seluruh dunia.

\section{Kesimpulan}

Konsep teologi yang dominan atau umum menjadi warna teologis kitab Rut adalah: pemeliharaan Tuhan, kasih setia (khesed), Penebus, kemisteriusan pekerjaan Tuhan dalam kehidupan umat-Nya, Daud dan leluhurnya ${ }^{10}$ yang menjadi jembatan Misi dan Gereja yang tidak dapat di pisahkan dan harus selalu berjalan secara bersamaan, dimana Amanat Agung dari Yesus kepada murid dan pengikut yaitu pergi dan membritahkan Injil. Gereja ada merupakan suatu tempat persekutuan orang percaya dan bukti dari iman mereka kepada Tuhan Allah, gereja mempunyai tugas utama yang sangat penting bukan hanya menjadi tempat

\footnotetext{
${ }^{9}$ Murah W. Downey, Cara -Cara Memenangkan Jiwa,(Bandung :Kalam Hidup,1957), h.5

${ }^{10}$ Rannu Sanderan." Pemahaman Tentang Sayap Dalam Kitab Rut: Studi Kritik Naratif." Kamasean : jurnal Teologi Kristen Volume 2, No 1, Juni 2021; (47-58)
} 
mendengarkan firman dan bersekutu tetapi juga keluar dan memberitahka Injil. Bermisi adalah tanggung jawab yang harus di lakukan yaitu membawa mereka yang terhilamg dan belum mengenal jalan keselamatan menuju kepada terang yang kekal yaitu Yesus Kristus. Kita adalah gereja itu sendiri atau orang yang percaya kita mempunyai tanggung jawab untuk memberitahkan Injil, jika Tuhan Yesus saja membritahkan kabar baik itu kenapa kita tidak bisa. Sebagai orang yang telah di selamatkan maka janganlah kita bersikap egois dan mengetahui keselamatan itu sendiri tetapi orang percaya akan menjadi murid yang sejati ketika mereka Memuridkan orang lain, dan membawa jiwa yang terhilang kepada keselamatan.

\section{SARAN}

Penulisan ini masih sangat jauh dari kata sempurna maka dari itu kritikan serta saran dari pembaca masih sangat saya butuhkan demi kelanjutan perbaikan tugas kedepannya.

\section{Daftar Pustaka}

\section{Kamus}

Kamus Besar Bahasa Indonesia. Pusat Pembinaan dan Pengembangan Bahasa. Jakarta: Balai Pustaka. 1995

\section{Buku Karangan}

Artanto, Widi. Menjadi Gereja yang Misioner. Jakarta: BPK Gunung Mulia. de Jong, Christian. Apa itu Calvinisme?. Jakarta: Gunung Mulia. 2001 De Kuiper, Arie. Missiologia: Ilmu Pekabaran Injil. Jakarta: Gunung Mulia. 2006.

J Bosch, David. Transformasi Misi Kristen. Jakarta: BPK Gunung Mulia. 2009

Kirk, J. Andrew. Apa Itu Misiologi?. Jakarta: Gunung Mulia. 2015

Patilima, Hamid. Metode Penelitian Kualitatif. Bandung: Alfabeta. 2011

Prastowo, Andi. Menguasai Teknik-Teknik Koleksi Data Penelitian Kulitatif.

Jogjakarta: DIVA Press. 2010

Proyek Pembinaan Calon Tenaga Kependidikan. Agama Kristen. Jakarta:

Sekretariat Jenderal Departement Agama RI. 2003

W. Downey, Murray. Cara-cara Memenangkan Jiwa. Bandung: Kalam Hidup. 